\title{
Laboratory measurements of 3-D flow patterns and turbulence in straight open channel with rough bed
}

\section{Mesures en laboratoire des configurations et de la turbulence des écoulements 3-D en canal ouvert avec lit rugueux}

\author{
JOSÉ F. RODRÍGUEZ, Lecturer, Civil and Environmental Engineering, School of Engineering, University of Newcastle, \\ University Drive, Callaghan, NSW, 2308, Australia. Tel.: 6124921 7376; fax: 6124921 6991; \\ e-mail: jose.rodriguez@newcastle.edu.au
}

\author{
MARCELO H. GARCÍA, (IAHR Member), Chester and Helen Siess Professor, V.T. Chow Hydrosystems Laboratory, University of \\ Illinois at Urbana-Champaign, 205 N. Mathews Ave., Urbana, IL 61802, USA. Tel.: 1217244 4484; fax: 1217 333 0687;
}

e-mail:mhgarcia@uiuc.edu

\begin{abstract}
Laboratory experiments have been carried out in order to study secondary circulation and flow variability in straight open channel flows over a rough bed. 3D flow velocities and turbulence characteristics were measured using a micro Acoustic Doppler Velocimeter. Two flow conditions were analyzed, with aspect ratios $b / h$ (width over depth) of 8.5 and 6.3, respectively. These two cases cannot be classified in principle as narrow $(b / h<5)$ or wide $(b / h>10)$ channel flows, but exhibited well defined secondary flows in the whole cross section. Bed shear stresses and turbulence patterns were consistent with the secondary flow cellular circulation. These results contradict the general perception that secondary circulation cells die out at a distance of $b>2.5 h$ from the walls. The behavior was attributed to the bed roughness $\left(k_{s} / h \sim 0.1\right)$ and to the difference in roughness between bed and walls, the latter being much smoother. The results allowed for quantification of hydrodynamic variability in terms of secondary velocities (5\% of mean flow velocity), cores of high streamwise velocities (10\% higher than surrounding flow) and bed shear stress ( $20 \%$ oscillation with respect to cross sectional averaged value). All these patterns are consistent with the very few results reported in the literature for similar roughness conditions. These results can be used to assess the background flow conditions existing in a straight channel with a plane bed, before the addition of pools and riffles as part of a restoration strategy for streams that have been channelized and do not present the flow variability needed to enhance habitat conditions.
\end{abstract}

\section{RÉSUMÉ}

Des expériences de laboratoire ont été effectuées en vue d'étudier la circulation secondaire et la variabilité des écoulements en canal rectiligne à surface libre sur un lit rugueux. Les vitesses 3D et les caractéristiques de la turbulence ont été mesurées en utilisant un micro Vélocimètre Acoustique Doppler. Deux conditions d'écoulement ont été analysées, avec des rapports $b / h$ (largeur sur profondeur) de 8.5 et de 6.3 , respectivement. Ces deux cas ne peuvent pas être classifiés en principe en tant qu'écoulement en canal étroit $(b / h<5)$ ou large $(b / h>10)$, mais ils comportaient des écoulements secondaires bien définis dans toute la section transversale. Les efforts de cisaillement de lit et les configurations de turbulence étaient conformes à la circulation cellulaire de l'écoulement secondaire. Ces résultats contredisent l'idée reçue de cellules de circulation secondaire s'éteignant à une distance des parois de $b>2.5 h$. Ce comportement a été attribué à la rugosité de lit $\left(k_{s} / h \sim 0.1\right)$ et à la différence de rugosité entre le lit et les parois, celles-ci étant beaucoup plus lisses. Les résultats ont permis de quantifier la variabilité hydrodynamique en termes de vitesses secondaires (5\% de la vitesse moyenne d'écoulement), de noyaux de courant à vitesses élevées (10\% de plus que l'écoulement environnant) et d'effort de cisaillement de lit (20\% d'oscillation par rapport à la valeur moyenne dans la section transversale). Toutes ces configurations sont conformes aux maigres résultats rapportés dans la littérature pour des états semblables de rugosité. Ces résultats peuvent être utilisés pour évaluer l'écoulement existant dans un canal rectiligne à fond plat, avant l'addition de bassins et de radiers en tant qu'éléments d'une stratégie de restauration pour des courants qui ont été canalisés et ne présentent pas la variabilité d'écoulement requise pour l'amélioration des conditions d'habitat.

Keywords: Laboratory experiments, rough bed, secondary circulation, straight open channels, turbulence

\section{Introduction}

The research presented herein has been motivated by a series of studies conducted for the restoration of a channelized urban stream in northeastern Illinois. The restoration of the West Fork of the North Branch of the Chicago River (WFNBCR) at Northbrook included the construction of pool-riffle structures (Wade et al., 2002; Rodríguez et al., 2000), designed to introduce flow variability and enhance habitat conditions. In-channel solutions were preferred in this project due to the limitations in plan-form alignment imposed by the existing infrastructure (i.e., parking lots, apartment buildings, etc.). A set of laboratory experiments was carried out to investigate the 3D flow structure of pools and riffles in support of the design process (Rodríguez et al., 2003 ; 2004). The experiments included several bed configurations, covering different levels of hydrodynamic complexity and 
also different stages in the restoration process. This paper presents the results of the flat bed experiments, which can be considered as the reference or pre-restoration condition. Since the restoration of the channelized stream was based on the addition of variability in the flow patterns through the construction of pools and riffles, the focus of the experiments was on the 3D structure of the flow and the quantification of the hydrodynamic variability for this particular stream.

Previous research (Prandtl, 1952; Perkins, 1970; Nezu and Nakagawa, 1993; Tamburrino and Gulliver, 1999) has shown that even the fairly simple case of a uniform, straight, channel flow can present cross sectional non uniformities in the principal velocity as a result of secondary currents. These secondary currents originate at the channel boundaries due to turbulence anisotropy and are referred to as secondary currents of Prandtl's second kind. They are of the order of $5 \%$ of the mean streamwise velocity and cannot sustain a size much larger than the flow depth (Nezu and Nakagawa, 1993). However, they have an important effect in altering the patterns of streamwise velocities, bed shear stresses, turbulence, and sediment transport.

Prandtl's secondary currents are also known as "corner flows" based on the analysis of non-circular duct flows (Schlichting, 1979). In a square duct, the secondary flow spans out from the center toward the corners, setting up a pair of vortices at each corner that convey the flow back into the main stream (Fig. 1(a)). As shown by Naot and Rodi (1982) secondary currents close to walls in rectangular open channels are quite different, with a strong free-surface vortex paired with a comparatively weaker bottom vortex (Fig. 1(b)). Wall and bottom roughness can affect the relative strength of the vortices (Naot, 1984).

In an open-channel flow, the anisotropy of turbulence is present in all the flow boundaries, i.e., side walls, bed, and free surface. Side wall effects are more important in narrow channels, while the bed effect is more important in the central region of wide channels. The exact boundary between wide and narrow channels is rather arbitrary and depends on the width over depth ratio $(b / h)$, with $b / h<5$ applying to narrow channels and $b / h>10$ corresponding to wide channels. Narrow channels present strong secondary circulation patterns and, as a result, the maximum velocities occur below the water surface (a phenomenon called "velocity dip") (Gibson, 1909; Chow, 1959). Wide channels have well-defined secondary currents close to walls but in the central region their effects may totally die out in the absence of spanwise variations of the bed shear stress, as shown by Nezu and Rodi (1985). However, often times the bed shear stress is induced to
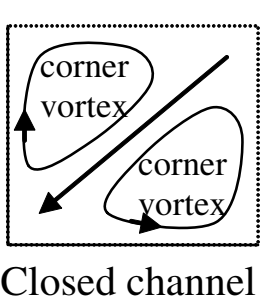

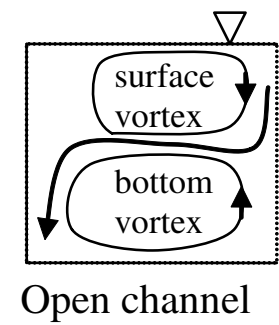

Open channel
Figure 1 Prandtl's second kind secondary circulation close to walls in closed and open channels
Table 1 Comparison between previous and current experiments

\begin{tabular}{lllllr}
\hline Reference & $b /\langle h\rangle$ & $R e \times 10^{3}$ & $F r$ & $k_{s} /\langle h\rangle$ & $\left\langle k_{s}^{+}\right\rangle$ \\
\hline $\begin{array}{l}\text { Naot (1984), } \\
\quad \text { experiment a }\end{array}$ & 4 & 100 & N/A & 0 & 0 \\
$\begin{array}{l}\text { Naot (1984), } \\
\quad \text { experiment c } \\
\begin{array}{c}\text { Tominaga } \text { et al. (1989), } \\
\quad \text { experiment S1 }\end{array}\end{array}$ & 8 & 16 & 0.57 & 0 & 0 \\
$\begin{array}{l}\text { Tominaga } \text { et al. }(1989), \\
\quad \text { experiment R21 }\end{array}$ & 8 & 12 & 0.51 & 0.24 & 210 \\
$\begin{array}{l}\text { This paper, } \\
\quad \text { experiment FB1 }\end{array}$ & 8.5 & 44 & 0.45 & 0.09 & 470 \\
$\begin{array}{l}\text { This paper, } \\
\text { experiment FB2 }\end{array}$ & 6.3 & 82 & 0.6 & 0.07 & 530 \\
\hline
\end{tabular}

vary periodically by causes such as flow instability or flow separation, and interactions with a mobile-bed can generate a stable secondary circulation pattern even in wide channels (McLelland et al., 1999).

Although it has long been recognized that the roughness of side walls and bed has an important effect in turbulence anisotropy and thus in secondary circulation, the extent of such influence has only been partially addressed. The few available systematic studies on the effects of uniformly distributed roughness in straight channels on mean flow secondary circulation are synthesized in Table 1 in terms of width over depth ratio, Reynolds number, Froude number, and dimensionless roughness. Naot (1984) numerically simulated secondary circulation in a straight narrow rectangular channel with $b / h=4$ and different roughness treatments along the walls and the bed. He found that the addition of uniform bed roughness with $k_{s} / h=0.015$ ( $k_{s}$ is the Nikuradse's roughness length) resulted in lateral velocities over the bed being slightly reduced close to a smooth wall in favor of an increase of flow over the wall. As pointed out by Nezu and Nakagawa (1993), the addition of roughness is responsible for the apparent strengthening of the free surface vortex at the expense of the bottom vortex. The fact that the roughness was relatively small (just enough to generate fully rough conditions since the roughness made dimensionless with the inner length scale $\left.k_{s}^{+}=k_{s} U_{*} / v=75\right)$ and that only one flow condition was analyzed, prevented a more conclusive explanation of the roughness effects on secondary circulation.

Tominaga et al. (1989) presented experiments on rectangular channels with different roughness treatments on the bed and walls and different aspect ratios. They measured the 3 components of the velocity vector (although not simultaneously) at several points in the cross section using an X-type (2D) hot-film sensor. For the case of smooth walls and bed and $b / h=8$ their measurements showed a strong secondary circulation in the region near the side walls, with a steady decay toward the center of the channel. Of the two paired vortices (Fig. 1), the surface vortex was notably weaker than the bottom vortex. The corresponding rough bed/smooth wall experiment with $k_{s} / h=0.24$ $\left(k_{s}^{+}=210\right)$ showed a sustained cellular secondary circulation 
pattern throughout the whole cross section. Near the side walls, the surface vortex was much stronger and larger than in the smooth bed case, almost obliterating the bottom vortex. Tominaga et al. (1989) did not provide any clear explanation about the mechanisms responsible for the maintenance of secondary circulation in the central region of the channel; instead they speculated about the possibility of slight irregularities in the bed roughness which could produce an effect similar to the presence of alternating smooth and rough stripes (Mclean, 1981; Studerus, 1982; Nezu and Nakagawa, 1993; Choi et al., 2006).

This paper presents a new set of data on the 3D flow structure observed in a straight open channel flow over a rough, flat bed. The present experiments replicate field conditions of interest for a restoration study, i.e. the one and two year floods, which resulted in rough flow conditions $\left(k_{s}^{+} \sim 500\right)$ with aspect ratios $b / h$ of 8.5 and 6.3, respectively. The experiments complement previous research (Table 1) and are particularly significant since they fall in between the commonly accepted categories of narrow and wide channels, an area that has not been thoroughly investigated in the past. They also present characteristics-in terms of $\mathrm{Fr}$ and $k_{s}^{+}$-typical of geomorphologically meaningful discharges (i.e., relatively high flows). The information provided herein should be useful for stream restoration projects in which the design is based on formative flow discharge events.

\section{Flow and turbulence in straight open channels}

Most of the knowledge about the fluid mechanics of open-channel flows strictly applies to $2 \mathrm{D}$ flows, i.e. flows with no variations in the spanwise direction. 3D flows in straight channels are not far removed from 2D flows and are typically analyzed using a 2D approximation as a starting point. The following analysis will focus on fully rough flow conditions, since this flow regime applies to both the laboratory experiments and the simulated field case. In this and the following sections, the notation for the vector components in the $x$ (streamwise), $y$ (spanwise), and $z$ (bed normal) directions are respectively $U, V$, and $W$ for the Reynolds averaged local velocities; $u, v$, and $w$ for the turbulent velocity fluctuations and $u^{\prime}, v^{\prime}$, and $w^{\prime}$ for the root mean square value of the velocity fluctuations. Whenever index notation is used $i=1,2$, and 3 stands for $x, y$, and $z$, respectively, so that $u_{1}=u, u_{2}=v, u_{3}=w$. Overbars are used for time averaging while brackets $\langle\bullet\rangle$ are used for spatial averaging.

Open-channel flows, like boundary layers and closed-channel flows, present two main regions: a near-wall (or inner) region, and an outer region (Nezu and Nakagawa, 1993). The characteristic that makes flow in open channels unique in terms of its outer structure is the presence of the free water surface, which acts as a confinement and defines a third surface-influenced layer where turbulence intensities and the turbulence length scale are modified (Nezu and Nakagawa, 1993). The wall region behaves in the same way as the classical inner layer in boundary-layer flows, which for the case of rough-flow conditions obeys the law of the wall with roughness length scale $k_{s}$ (Nikuradse's equivalent sand roughness (Nikuradse, 1933)) and velocity scale $U_{*}$ (shear velocity), as follows (Garcia, 1999):

$$
\frac{U}{U_{*}}=\frac{1}{\kappa} \ln \left(\frac{z}{k_{s}}\right)+8.5,
$$

where $\kappa$ is the von Karman's constant. The turbulence structure of this region is characterized by intense turbulent bursting, resulting in turbulent energy production $G$ being greater than the turbulent dissipation rate $\varepsilon$ (Lopez and Garcia, 1999).

The free-surface region is controlled by the outer variables $U_{\max }$ (maximum mainstream velocity) and $h$, and a velocitydefect law with wake correction can be applied irrespective of roughness conditions:

$$
\frac{U_{\max }-U}{U_{*}}=-\frac{1}{\kappa} \ln \left(\frac{z}{h}\right)+\frac{2 \Pi}{\kappa} \cos ^{2}\left(\frac{\pi z}{2 h}\right),
$$

where $\Pi$ is Coles' wake strength parameter. The turbulence budget for this region presents $G<\varepsilon$, thus requiring supply of turbulent energy from the wall region by turbulent diffusion.

The intermediate region, with velocity scale $U_{*}$ and length scale $z$, is not strongly influenced by either the wall or the freesurface properties, accepting both the law of the wall and the velocity-defect law. The turbulence budget is in equilibrium with $G \approx \varepsilon$, a reason why this layer is also known as the equilibrium layer. Some universal turbulence characteristics in this region are given by (Nezu and Nakagawa, 1993):

$$
\begin{aligned}
\frac{-\overline{u w}}{U_{*}^{2}} & =1-\frac{z}{h} \\
\varepsilon_{x z} & =k h U_{*} \frac{z}{h}\left(1-\frac{z}{h}\right) \\
\frac{u_{i}^{\prime}}{U_{*}} & =D_{i} \exp \left(-C_{k} \frac{z}{h}\right),
\end{aligned}
$$

where $\varepsilon_{x z}$ is the $x-z$ component of the eddy viscosity tensor, and $C_{k}$ and $D_{i}$ are empirical constants $\left(C_{k} \approx 1, D_{1} \approx 2.3\right.$, $D_{2} \approx 1.63$, and $D_{3} \approx 1.27$, according to Nezu and Nakagawa, 1993). Equation (5) has been derived for smooth flow regime, and limited experimental evidence under rough flow conditions indicates that it still applies.

Also valid within the equilibrium layer is López and García (1999) formulation for wall similarity, which leads to a constant normalized flux of turbulent kinetic energy independent of wall roughness and given by:

$$
-\frac{1}{2} \frac{\overline{q^{2} w}}{U_{*}^{3}}=A^{+} \cong 0.33,
$$

where $q^{2}=u^{2}+v^{2}+w^{2}$ is twice the instantaneous value of the turbulent kinetic energy. Further assuming a gradient flux model for the turbulent kinetic energy results in expressions for the wall-normal distribution of the three turbulent intensities:

$$
\left(\frac{u_{i}^{\prime}}{U_{*}}\right)^{2}=-C_{i} \frac{A^{+}}{\kappa} \ln \left(\frac{B^{+} z / h}{1-z / h}\right),
$$

where $B^{+} \approx 0.12, C_{1} \approx 1.10, C_{2} \approx 0.56$, and $C_{3} \approx 0.34$ (López and García, 1999).

$3 \mathrm{D}$ flow patterns in straight channels appear in the form of secondary currents. The streamwise vorticity $\Omega \equiv \partial V / \partial z-\partial W / \partial y$, 
can be used to study the different mechanisms producing secondary circulation in open channels, as originally proposed by Einstein and Li (1958). For straight uniform flow in an infinitely wide channel $\Omega$ is purely induced by turbulence, and the following relation holds (Ikeda, 1981):

$$
\frac{\partial^{2}}{\partial y \partial z}\left(v^{\prime 2}-w^{\prime 2}\right)=\left(\frac{\partial^{2}}{\partial y^{2}}-\frac{\partial^{2}}{\partial z^{2}}\right) \overline{v w},
$$

where the production of $\Omega$ by turbulence anisotropy (left-hand side) is balanced by the suppression of $\Omega$ by the Reynolds stresses $\overline{v w}$. Using an eddy viscosity model the higher order terms $\overline{v w}$ can be approximated as:

$$
-\overline{v w}=\varepsilon_{y z}\left(\frac{\partial W}{\partial y}+\frac{\partial V}{\partial z}\right),
$$

with $\varepsilon_{y z}$ being the $y-z$ component of the eddy viscosity tensor. For the vorticity generation term, Ikeda (1981) used the following equation assuming a linear distribution of the Reynolds stresses $\overline{u w}$ (Eq. (3)):

$$
\frac{v^{\prime 2}-w^{\prime 2}}{U_{*}^{2}} \cong \frac{-\overline{u w}}{U_{*}^{2}}=1-\frac{z}{h} .
$$

Ikeda (1981) solved theoretically the set of Eqs (8)-(10) using a depth-averaged eddy viscosity $\varepsilon_{y z}=\kappa\left\langle U_{*}\right\rangle h / 6$ and a sinusoidal spanwise distribution of the bottom shear stress (which enters the equations through its surrogate the shear velocity $U_{*}$ ), i.e.,

$$
\frac{\tau}{\langle\tau\rangle}=1+\delta \cos \left(\frac{k_{b} y}{h}\right),
$$

where $\delta$ is the amplitude of the sinusoidal distribution and $k_{b}$ is the wave number. For the dominant cells $\left(k_{b}=\pi\right)$, Ikeda obtained a pattern of cellular secondary circulation given by:

$$
\begin{aligned}
\frac{V}{\left\langle U_{*}\right\rangle} & =\frac{6 \delta}{\kappa \pi^{2}} \sin \frac{\pi y}{h}\left[\frac{2}{\pi} \cos \frac{\pi z}{h}-\left(2 \frac{z}{h}-1\right) \sin \frac{\pi z}{h}\right] \\
\frac{W}{\left\langle U_{*}\right\rangle} & =\frac{6 \delta}{\kappa \pi^{2}} \cos \frac{\pi y}{h}\left[\left(2 \frac{z}{h}-1\right) \cos \frac{\pi z}{h}+1\right] .
\end{aligned}
$$

Equations (12) and (13) describe circular counter rotating cells of diameter $h$. Although the resulting cells correspond to an idealized case, they reproduce key elements observed in boundary layers, closed conduits, and open channel flows. Of particular importance is the correlation between bottom shear stresses and the vertical velocity component given by a shear-stress increase in regions of downwelling and a decrease in regions of upwelling, which is in agreement with the ideas of Perkins (1970) and Townsend (1976) for boundary layers and experimental evidence in closed flows (Nezu and Nakagawa, 1984) and open-channel flows (Nezu and Rodi, 1985). Note that a number of simplifications have been made in order to arrive at the solution and perhaps the most drastic is the feedback effect of secondary circulation on the wall shear stress (Nezu and Nakagawa, 1993, p. 89), which could provide a mechanism for the self-sustainability of secondary currents. That feedback is through the Reynolds stresses $\overline{u w}$, which are influenced by turbulence anisotropy as shown by Eq. (10). In fact, $\overline{u w}$ deviates from Eq. (3) in the presence of secondary currents. The deviation is such that points in the upflow regions have higher values of $\overline{u w}$ than those predicted by Eq. (3), whereas points in the downflow regions have lower values (Nezu and Nakagawa, 1993). More sophisticated models exist for the description of turbulence-induced secondary circulation, but they rely on semi-empirical equations for the transverse Reynolds stresses (Tominaga et al., 1989; Jin et al., 2004).

In the following sections the obtained data will be compared with some of the formulations presented above, in order to address their predictive capabilities and limitations. Also the mechanism for the self sustainability of secondary currents in the present setup will be investigated.

\section{Experimental setup and methods}

A tilting flume $12.20 \mathrm{~m}$ long, $0.91 \mathrm{~m}$ wide and $0.6 \mathrm{~m}$ high was used for the experiments. The flume received a constant supply of water from a head tank and had an adjustable downstream gate to regulate the flow depth. Commercial 3/8" crushed stone chips $\left(D_{90}=1 \mathrm{~cm}, D_{m}=0.57 \mathrm{~cm}\right.$, and $\left.\sigma_{g}=0.20 \mathrm{~cm}\right)$ were used to provide a fixed, hydraulically rough bed (see Table 1 for roughness values). The experimental setup was completed with point gauges for water surface measurements and a Sontek micro Acoustic Doppler Velocimeter (ADV) for flow velocity measurements. The micro ADV was operated at a sampling rate of $25 \mathrm{~Hz}$ over a $70 \mathrm{~mm}^{3}$ sampling volume. Orientation was done so that the instrument's $z$ coordinate coincided with the vertical and the $x$ and $y$ coordinates were aligned with the horizontal projections of the streamwise and spanwise channel coordinates, respectively. Due to minimum flow depth requirements for the sensor, the upper $6 \mathrm{~cm}$ of the flow could not be measured. Velocities were measured every $1 \mathrm{~cm}$ in the vertical direction and every $5 \mathrm{~cm}$ in the spanwise direction on one half of the cross section, after verifying symmetry of the velocity distribution with respect to the channel centerline. Water surface elevations were measured at several points along the channel centerline only, since the transverse variations on the water surface were too small to be measured accurately.

A summary of the experimental conditions is presented in Tables 1 and 2. In these tables, $S_{0}$ is the slope of the flume, $Q$ is the discharge, $\langle U\rangle$ is the cross-sectional mean streamwise velocity, $\left\langle U_{*_{s}}\right\rangle=\left(g R_{h} S_{0}\right)^{1 / 2}$ is the cross-sectional streamwise shear velocity based on the slope, with $g$ and $R_{h}$ being, respectively the gravitational acceleration, and the hydraulic radius; $R e=$ $\langle U\rangle R_{h} / v$ is the bulk Reynolds number, with $v$ denoting kinematic viscosity of water; $F r=\langle U\rangle /(g\langle h\rangle)^{1 / 2}$ is the Froude number, with $\langle h\rangle$ standing for the hydraulic depth; $\left\langle k_{s}^{+}\right\rangle=k_{s}\left\langle U_{*_{s}}\right\rangle / v$ is the cross-sectional dimensionless roughness, with $k_{s}$ representing the

Table 2 Flow conditions for the present experiments

\begin{tabular}{llllllll}
\hline Experiment & $\begin{array}{l}S_{0} \\
(\%)\end{array}$ & $\begin{array}{l}D_{90} \\
(\mathrm{~cm})\end{array}$ & $\begin{array}{l}Q \\
(\mathrm{l} / \mathrm{s})\end{array}$ & $\begin{array}{l}\langle h\rangle \\
(\mathrm{cm})\end{array}$ & $\begin{array}{l}\langle U\rangle \\
(\mathrm{cm} / \mathrm{s})\end{array}$ & $\begin{array}{l}\left\langle U_{*_{s}}\right\rangle \\
(\mathrm{cm} / \mathrm{s})\end{array}$ & $\begin{array}{l}\left\langle T_{u}\right\rangle \\
(\mathrm{sec})\end{array}$ \\
\hline FB1 & 0.25 & 1 & 50 & 11 & 48 & 5 & 0.18 \\
FB2 & 0.25 & 1 & 110 & 15 & 72 & 5.5 & 0.16 \\
\hline
\end{tabular}


bed roughness (set equal to $D_{90}$ for the present computations); and $\left\langle T_{u}\right\rangle=0.77\langle h\rangle /\langle U\rangle$ is a cross-sectional macro timescale of the flow in the streamwise direction (Nezu and Nakagawa, 1993).

For the two flow conditions tested the discharges were 0.05 (FB1) and 0.11 (FB2) $\mathrm{m}^{3} / \mathrm{s}$. As already explained, the low and high discharges resulted from converting to a 1/7 Froude scale the one- and two-year return-period floods for the WFNBCR at Northbrook, Chicago, respectively. Table 1 shows that in both experiments the flow was turbulent and subcritical and the bed was hydraulically rough, with values of $\left\langle k_{s}^{+}\right\rangle$well above 70 (Nezu and Nakagawa, 1993). Aspect ratios $b /\langle h\rangle$ were in between the "narrow" and "wide" channel classifications and the relative roughness $k_{s} / h$ was around $10 \%$, far greater than in Naot (1984) experiments and closer to the value used by Tominaga et al. (1989).

Measurements were carried out at a test section located $6 \mathrm{~m}$ downstream from the channel entrance where the flow was uniform, with the slope of the water surface parallel to the slope of the flume $S_{0}$ and the boundary layer fully developed. Each velocity point was sampled for at least $120 \mathrm{~s}$. This record length was of the order of 600 times the estimated macro timescales of the flow $\left\langle T_{u}\right\rangle$ (Table 2), ensuring the computation of reliable estimates of the mean, variance, and covariances of the velocity time series (Garcia et al., 2005).

Shear velocities were computed using different methodologies, i.e. law of the wall, Reynolds stresses, and energy slope. Indirect determination of shear velocities using the law of the wall can be problematic over rough beds (Smart, 1999), since three unknowns must be determined simultaneously: the position of the bed, $k_{s}$ and $U_{*}$. The ADV provides a reading of the distance from the sensor to the bottom, and that reading could have been used to position the bed; however, the accuracy of that reading was very poor due to small scale irregularities of the bed material and was not used. Instead, an optimization procedure was implemented to determine the position of the bed based on the position of the top of the roughness elements (TRE), which was easier to measure. Each velocity profile was first analyzed allowing for the simultaneous variation of the position of the bed and $k_{s}$ until the correlation coefficient of a logarithmic fit (law of the wall) was maximized. The maximization was carried out using the solver add-in feature of Microsoft Excel, letting the position of the bed vary between 0 and $k_{s}$ below TRE and $k_{s}$ vary between $D_{90}$ and $3 D_{90}$ (Smart, 1999). TRE was determined before inundating the channel bed by leveling a flat board laid across the channel on top of the stone chips and subtracting the board thickness. The value of $k_{s} \sim D_{90}$ was consistently obtained, while the position of the bed fluctuated around $0.3 D_{90}$. Final computations were performed using $k_{s}=D_{90}$ and letting the position of the bed adjust to maximize the correlation coefficient.

Cross-sectional averaged values of the shear velocity obtained from velocity profiles were compared with values computed using the vertical profiles of Reynolds stresses $\overline{u w}$ and the energy slope after wall correction using the method of Vanoni and Brooks (Vanoni, 1975). The values agreed within 10\%, as shown in Table 3, where $\left\langle U_{* b}\right\rangle,\left\langle U_{*}\right\rangle$, and $\left\langle U_{* r}\right\rangle$ correspond to energy slope
Table 3 Bed component of the cross-sectional averaged shear velocity computed using energy slope, $\left\langle U_{* b}\right\rangle, \log$ law, $\left\langle U_{*}\right\rangle$, and Reynold stresses, $\left\langle U_{* r}\right\rangle$

\begin{tabular}{llll}
\hline Experiment & $\begin{array}{l}\left\langle U_{*_{b}}\right\rangle \\
(\mathrm{cm} / \mathrm{s})\end{array}$ & $\begin{array}{l}\left\langle U_{*}\right\rangle \\
(\mathrm{cm} / \mathrm{s})\end{array}$ & $\begin{array}{l}\left\langle U_{*_{r}}\right\rangle \\
(\mathrm{cm} / \mathrm{s})\end{array}$ \\
\hline FB1 & 5 & 4.5 & 4 \\
FB2 & 6 & 6 & 5.5 \\
\hline
\end{tabular}

(bed component only after wall correction), velocity profile, and Reynolds stress profile methods, respectively.

\section{Results}

\subsection{Mean flow}

Secondary flow velocities in a straight channel are only a small fraction of the streamwise velocity, so any minor misalignment of the sensor can result in severe contamination of the transverse velocity field. Pre-processing of the ADV velocity data included rotation from a vertical (instrument-based) to a bed-normal system of reference and a correction for streamwise misalignment of the instrument. The first adjustment is fairly straightforward since the rotation angle is known (angle between the vertical and the bed-normal direction), but the second originates in an error angle which is difficult to measure. Error angles for each vertical profile were explored by plotting the ADV's streamwise and spanwise velocity components for all measurements points in the vertical and fitting a straight line to the data, the slope of the straight line representing the error angle. Error angles for all verticals were less than 0.04 radians and did not affect the data substantially. Finally, visual inspection of the whole secondary flow velocity field was conducted to check for mass conservation (no transverse net flow) on one half of the cross section. A formal mass conservation check could not be carried out due to the lack of velocity data closer to the water surface.

Figure 2 shows dimensionless profiles of mean streamwise velocities at different transverse locations $y / b$ for low and high flow. The data can be collapsed using the inner scaling variables $U_{*}$ (local value) and $k_{s}$ and the law of the wall for hydraulically rough conditions (Eq. (1)). Irrespective of the spanwise position, the streamwise velocity data also follows the outer velocity-defect law (Eq. (2)) without the need for a wake correction (Fig. 3). $U_{\max }$ in Fig. 3 has been estimated extrapolating the logarithmic profile all the way to the water surface.

Bed shear stresses computed using the shear velocity values obtained from the law of the wall (as described in the previous section) are shown in Fig. 4. In both the low and the high flow cases, the spanwise distribution of the wall shear stress is not uniform but oscillates around the cross sectional average $\langle\tau\rangle$. Included in the figure are sinusoidal fits to the wall shear stress distributions (Eq. (11)) with $k_{b}=\pi$ and $\delta$ values of 0.15 and 0.20 for low and high flow, respectively. Note that in the case of the low flow the $y$ coordinate in Eq. (11) has been shifted by a constant in order to match the data. 
a)

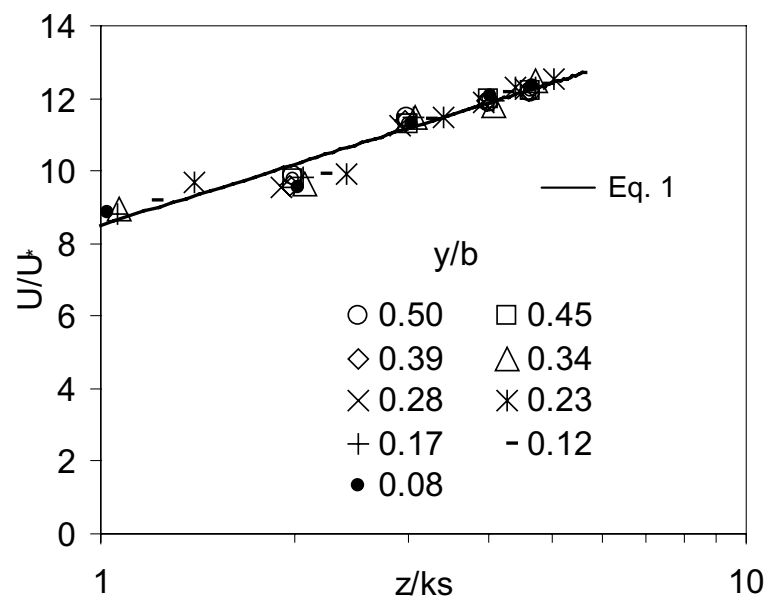

b)

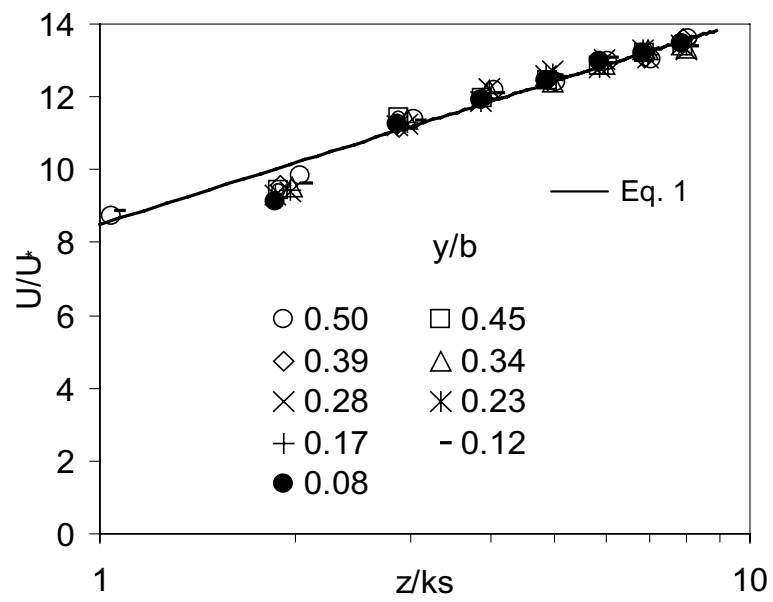

Figure 2 Dimensionless streamwise velocity profiles (inner scaling): (a) low flow, (b) high flow. Comparison with Eq. (1)

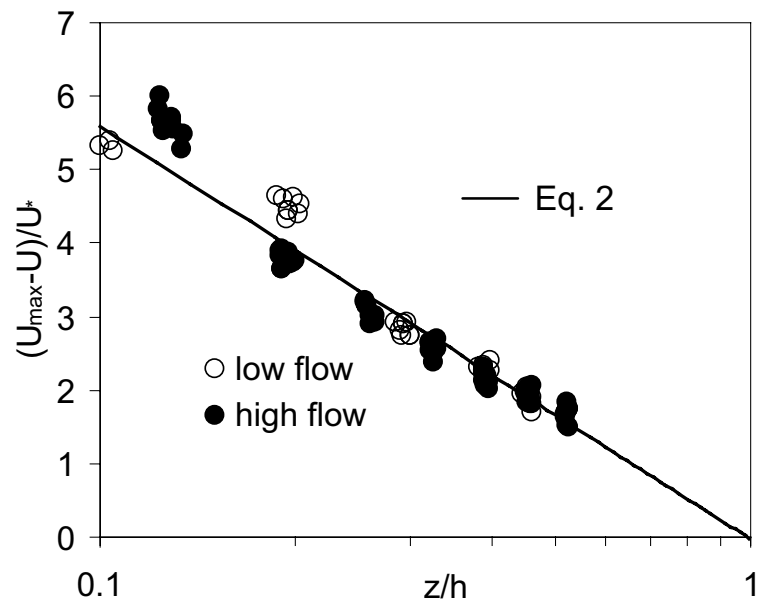

Figure 3 Streamwise velocities (outer scaling). Comparison with Eq. (2)

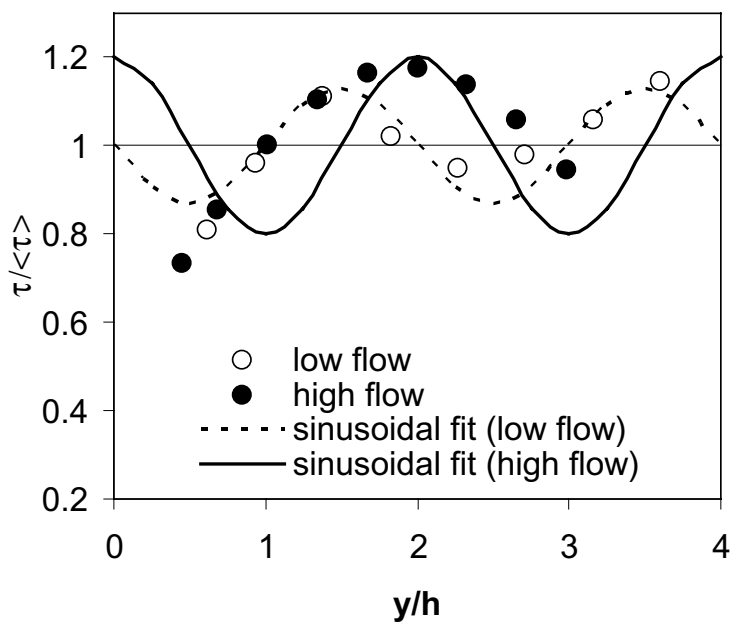

Figure 4 Transverse distribution of bed shear stresses and fit of sinusoidal distributions to the experimental data

Secondary flow patterns in the form of velocity vectors are presented in Fig. 5. The vectors have been normalized with the cross sectional average shear velocity $\left\langle U_{*}\right\rangle=(\langle\tau\rangle / \rho)^{0.5}$ and the $y$ and $z$ coordinates have been made dimensionless with the flow
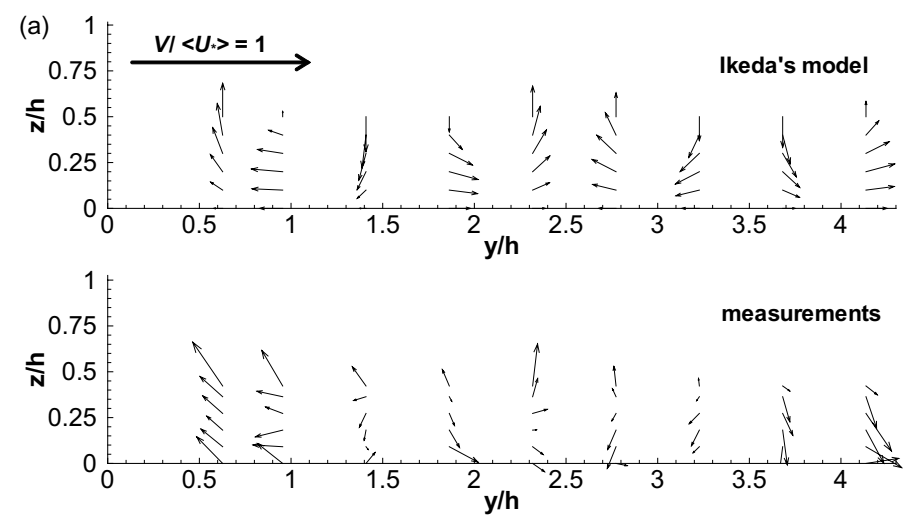

(b)
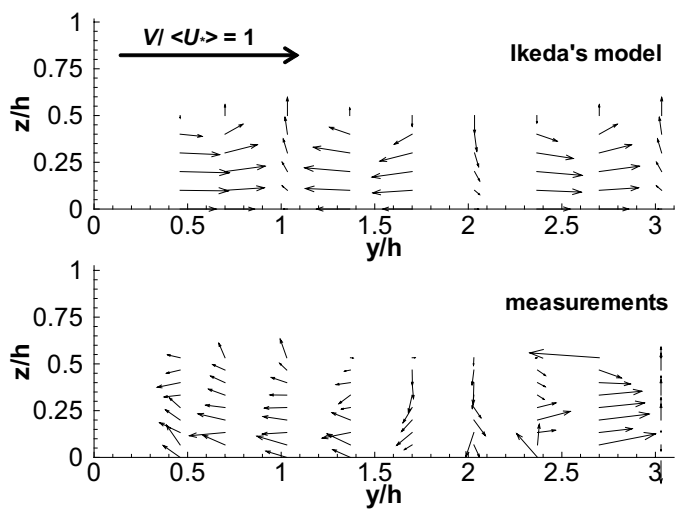

Figure 5 Secondary currents divided by $\left\langle U_{*}\right\rangle$ : (a) low flow, (b) high flow

depth $h$. Ikeda's model predictions (Eqs (12) and (13)) using the sinusoidal wall shear stress distributions of Fig. 4 have been included for comparison. Similarly to Eq. (11), the $y$ coordinate in Eqs (12) and (13) has been shifted for the case of the low flow.

The $3 \mathrm{D}$ cross sectional structure for the low and high flows is presented in Fig. 6 as a combined contour-vector plot: contours for the streamwise velocity and vectors for the secondary velocities. The streamwise velocity distributions are organized around several, regularly spaced cores of high velocity. These high velocity zones are about $10 \%$ faster than the surrounding flow and are associated with regions of downward flow and high wall shear stress (Fig. 4). 


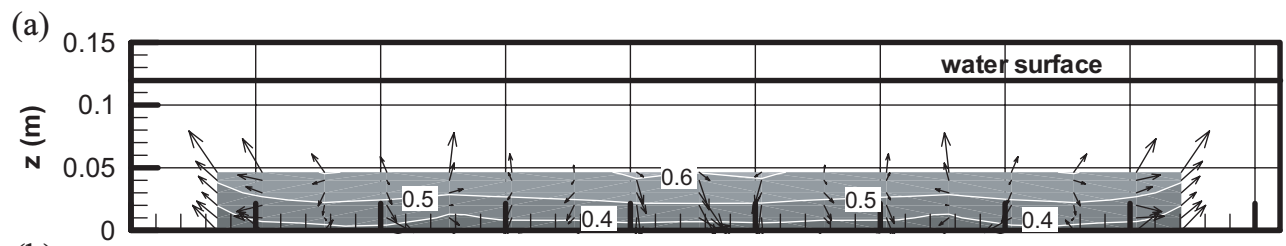

(b)

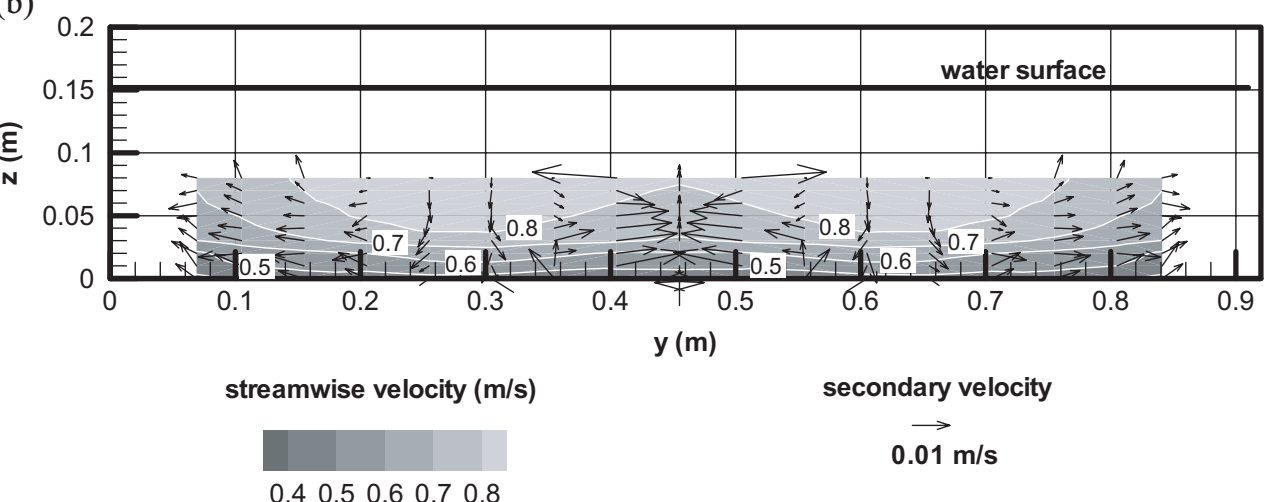

Figure 6 Cross sectional velocity distribution for: (a) low flow, (b) high flow
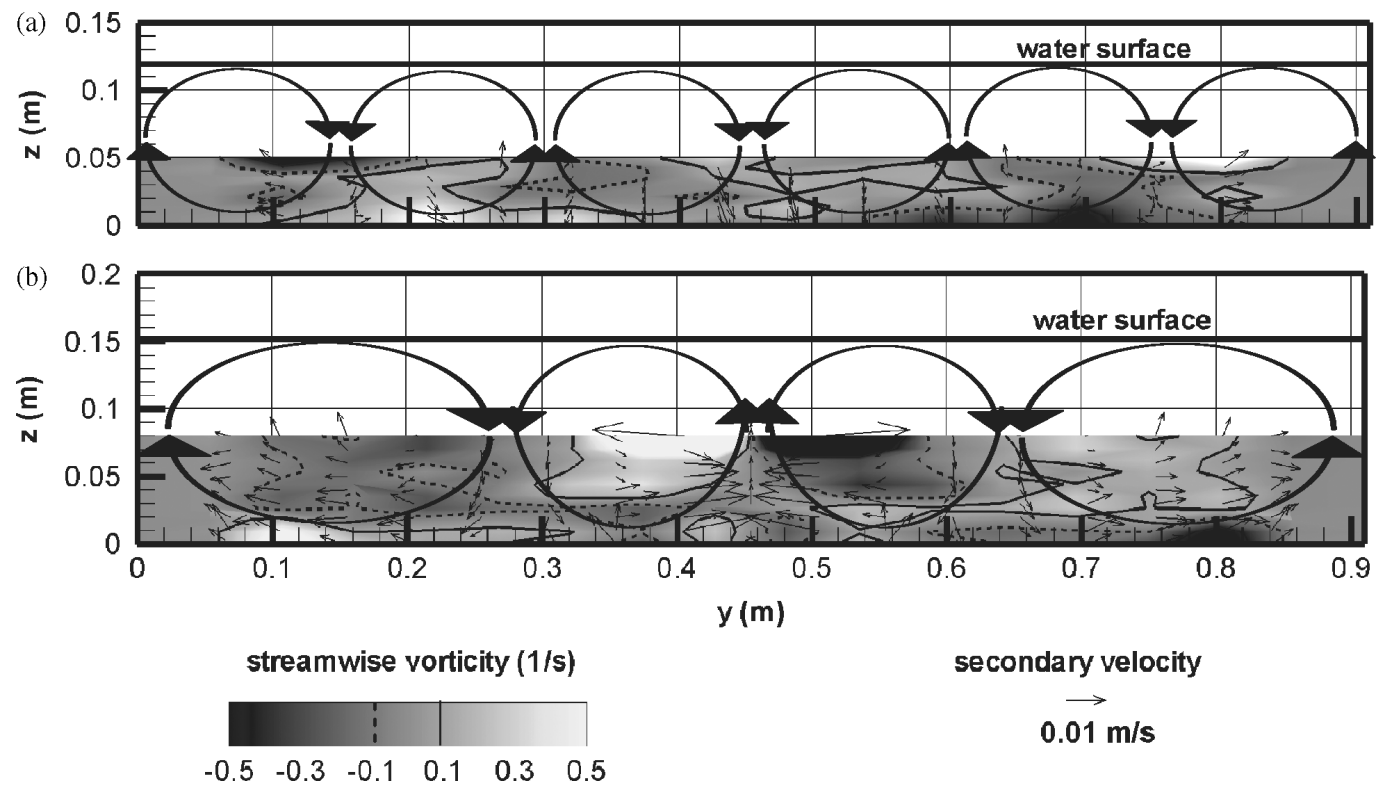

secondary velocity

$0.01 \mathrm{~m} / \mathrm{s}$

Figure 7 Streamwise vorticity distribution for: (a) low flow, (b) high flow. Solid and dashed contour lines correspond to $0.1 \mathrm{~s}^{-1}$ and $-0.1 \mathrm{~s}^{-1}$

Secondary circulation is characterized by the presence of cellular cells, scaling approximately with the flow depth and producing upwelling along the lateral walls. The secondary velocities are very small, only a small percentage of the streamwise component. They are not strong enough to modify the streamwise velocity profile, which is logarithmic as in the case of two dimensional flows.

The streamwise vorticity distribution can be used to help identify recirculation cells. Within the cross section, a cell with positive longitudinal vorticity rotates counterclockwise, whereas a negative vorticity cell rotates in the opposite direction. Figure 7 presents contour plots of the streamwise vorticity $\Omega$ Computed using centered derivatives in $V$ and $W$. Rotating cells have been sketched in the figures, combining information on the transverse velocity vector field and the streamwise vorticity.

\subsection{Turbulence}

Streamwise Reynolds stresses $\overline{u w}$ made dimensionless with the local value of $U_{* r}$ squared are shown in Fig. 8, together with the predictions of Eq. (3). Figure 9 shows the values of $\varepsilon_{x z}$ obtained from the measurements $[-\overline{u w} /(d U / d z)]$ and compares them with the analytical expresion derived from the logarithmic law (Eq. (4)) and also Ikeda's formulation for $\varepsilon_{y z}$.

Normalized vertical fluxes of turbulent kinetic energy $-\overline{q^{2} w} / 2 U_{*}^{3}$ as a function of depth are plotted in Fig. 10, where the universal value proposed by Eq. (6) has also been included. The flux $-\overline{q^{2} w} / 2$ is a third-order statistics, and direct computation of higher order statistics would have required longer sampling records than the ones used in these experiments (García et al., 2005). For that reason, the flux was computed using a 
a)

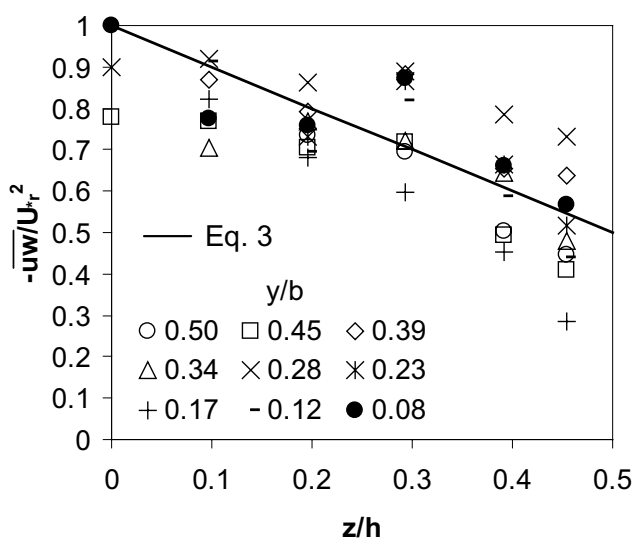

b)

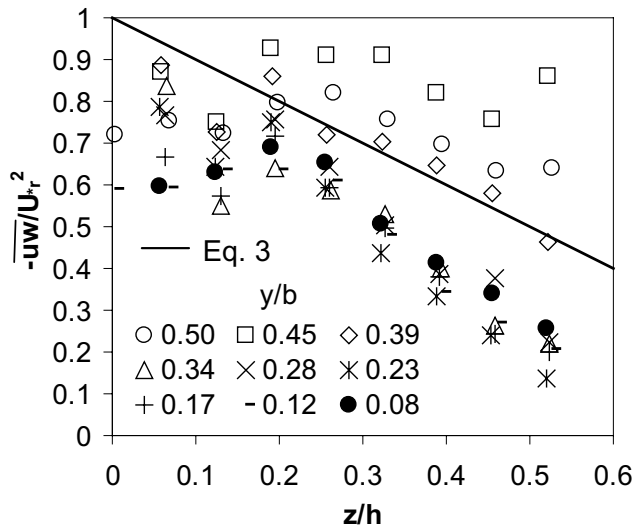

Figure 8 Dimensionless streamwise Reynolds stresses for: (a) low flow, (b) high flow. Comparison with Eq. (3)
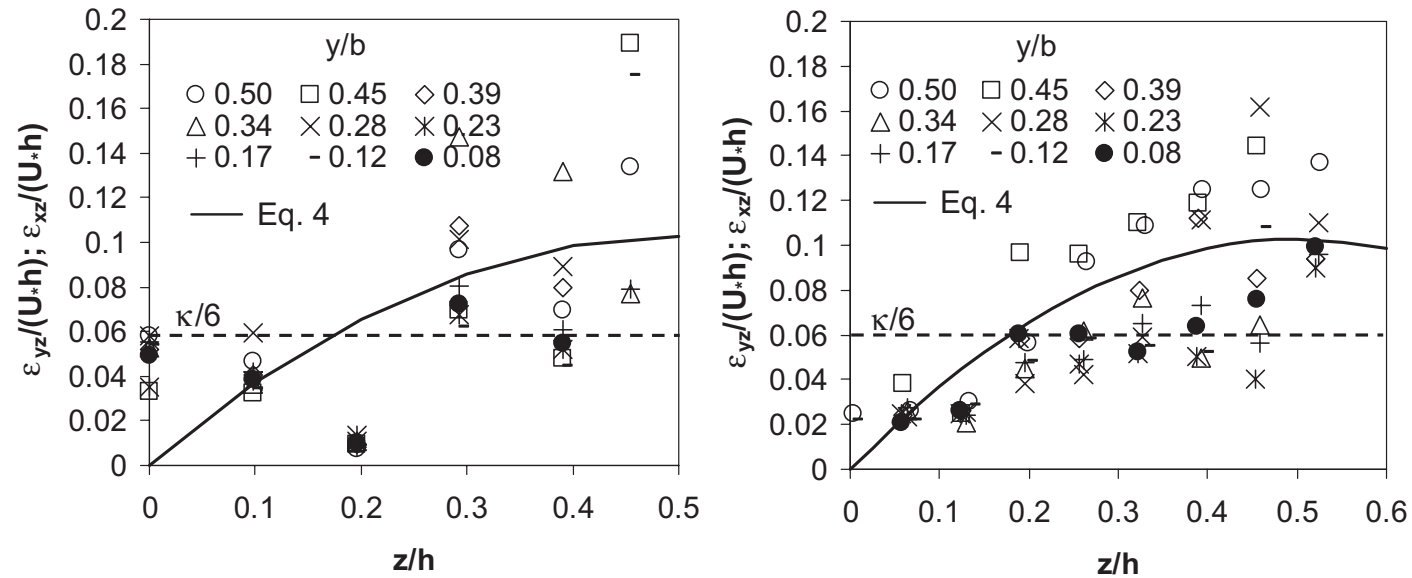

Figure 9 Dimensionless turbulent viscosity for: (a) low flow, (b) high flow. Comparison with Eq. (4) and mean vertical value given by Ikeda (1981)

a)

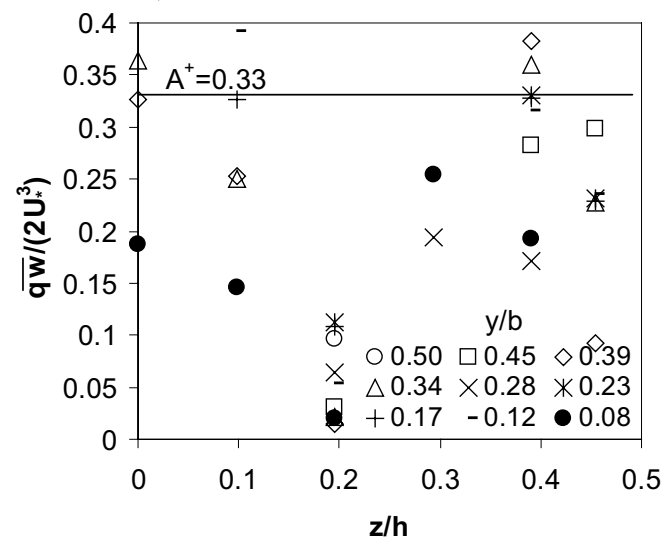

b)

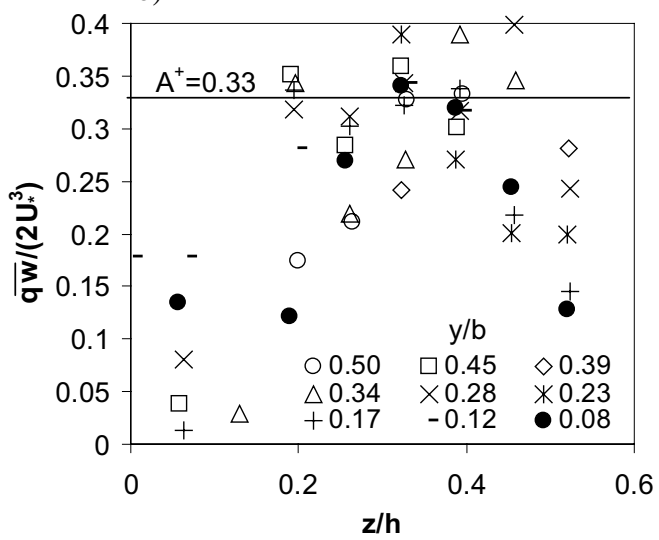

Figure 10 Dimensionless flux of turbulent kinetic energy for: (a) low flow, (b) high flow. Comparison with the theoretical value of $A^{+}$given by López and García (1999)

gradient-diffusion model following López and García (1999):

$$
-\overline{q^{2} w} / 2=\frac{\varepsilon_{x z}}{\sigma_{k}} \frac{d\left(\overline{q^{2}} / 2\right)}{d z},
$$

where $\sigma_{k}$ is the ratio between the turbulent diffusivity of turbulent kinetic energy and momentum, typically assumed to be 1.
Normalized profiles of streamwise turbulence intensities are plotted in Fig. 11. The curves in the figure correspond to Eq. (5) (equilibrium assumption with $C_{k}=1$ and a value of $D_{u}$ obtained by data fitting) and to Eq. (7) (wall similarity assumption).

In a straight flow configuration, secondary currents are the result of turbulence anisotropy at the walls and at the water surface. The driving force per unit mass due to turbulence anisotropy 
a)

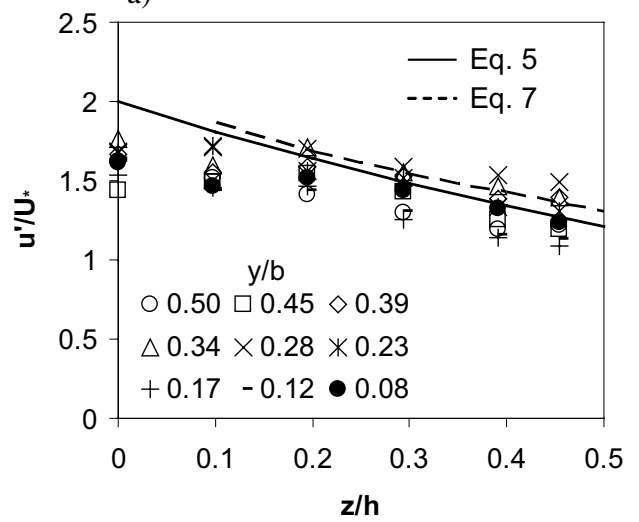

b)

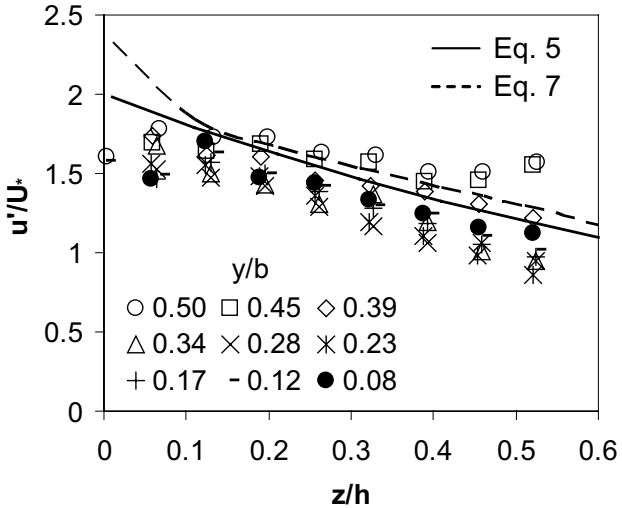

Figure 11 Dimensionless streamwise turbulent intensities for: (a) low flow, (b) high flow. Comparison with Eqs. (5) and (7)

a)

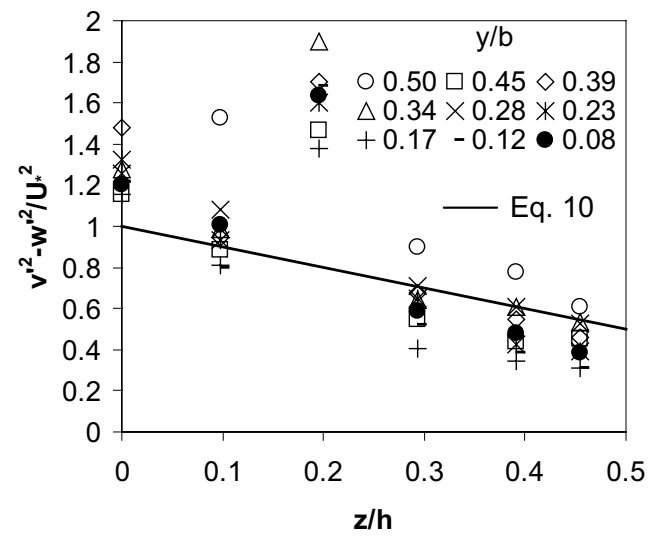

b)

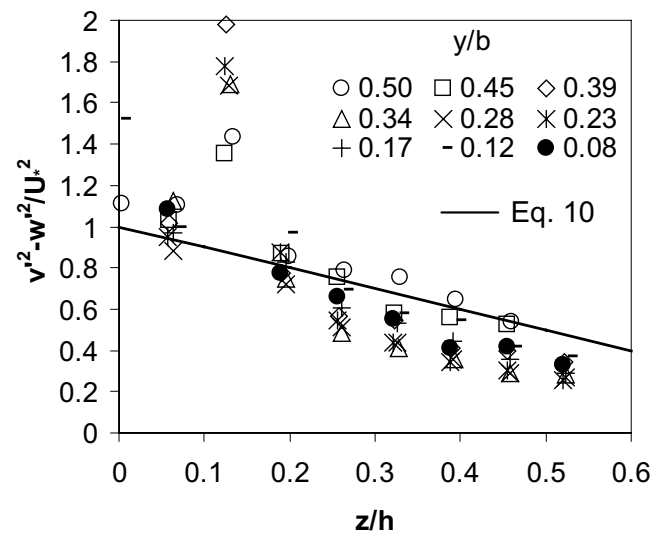

Figure 12 Dimensionless turbulence anisotropy for: (a) low flow, (b) high flow. Comparison with Eq. (10)

$v^{\prime 2}-w^{\prime 2}$ normalized with $U_{*}^{2}$ is plotted in Fig. 12, which also includes Eq. (10).

\section{Discussion}

Both inner and outer scaling variables provide a good collapse of the data, as shown by Figs 2 and 3, respectively. The region of the flow measured does not seem to be affected by the water surface, and no wake function is required. The fact that the streamwise velocity accepts both inner and outer scaling confirms that the data corresponds to the intermediate region. It can be noticed that some points plot away from the similarity curves in both figures. Those points are located at approximately $2.5-3 \mathrm{~cm}$ from the bottom, a distance at which sound reflection from the bottom interferes with the ADV readings. All measurements taken at that distance must be discarded as inaccurate readings.

The shear stress distribution of Fig. 4 is in agreement with results presented elsewhere (Nezu and Nakagawa, 1993; Tominaga et al., 1989). An oscillating pattern reveals the importance of the secondary flow in redistributing momentum within the cross section. Sinusoidal fits to the curves requires the use of $\delta$ values of 0.15 and 0.20 for low and high flow, respectively. The wall shear stress oscillation amplitude (given by $\delta$ ) increases

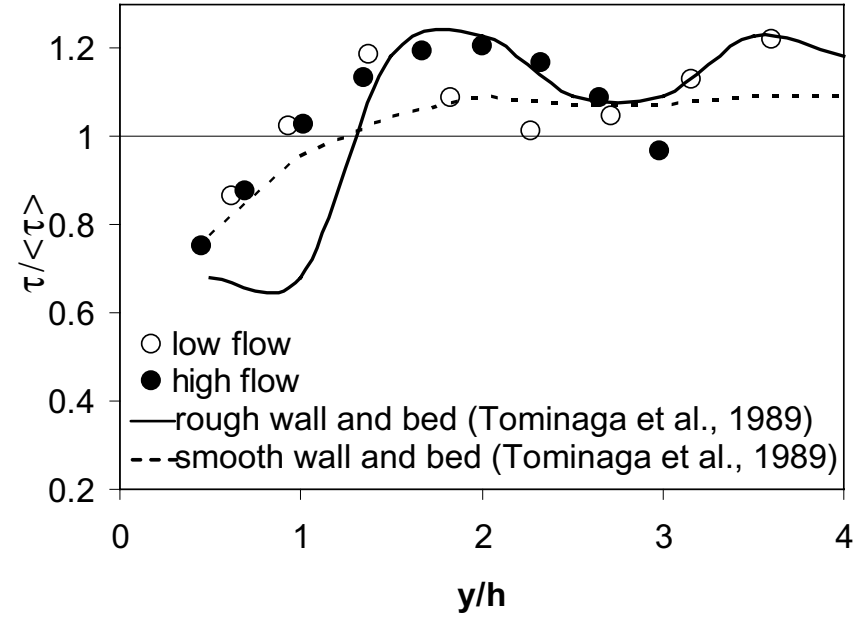

Figure 13 Transverse distribution of bed shear stresses. Comparison with results from Tominaga et al. (1989) for different wall and bed roughness treatments

with roughness $k_{s}^{+}$, as shown by Fig. 13, in which results from Tominaga et al. (1989) have been included. The results from Tominaga et al. (1989) correspond to similar roughness treatments in bed and walls, explaining a stronger wall damping effect for the rough case when compared to the present experiments. 
Ikeda's model does not account for the presence of the lateral walls, so only the data away from the walls $(y / h>1)$ was used for the sinusoidal fit. Ikeda's model (Eqs (12) and (13)) does a good job in predicting the recirculation pattern of Fig. 5, particularly when the regions close to the lateral walls $(y / h<1)$ are not included in the analysis.

Even under a simple flow configuration like the one analyzed in this paper, there is quite a variability in the velocity patterns when looking at the cross sectional data (Fig. 6). The secondary flow affects the vertical transfer of momentum and thus the principal velocity distribution, but the logarithmic law still holds. Secondary circulation presents cells that are almost circular with an alternating rotation, as shown by the streamwise vorticity plots of Fig. 7. Cells scale with the cross-sectional flow depth, resulting in 6 cells for the low flow and 4 cells for the high flow. Cores of high longitudinal velocity are located in the downwelling zones between cells. Some cells stretch slightly in the spanwise direction so that the lateral distance between two consecutive cells is 1-1.5 times the flow depth $h$. Bed shear stress patterns are in total synchronicity with the 3D velocity distribution, with higher and lower values coinciding, respectively with regions of flow downwelling and upwelling.

The picture is completed with the analysis of the turbulence data. The 2D assumption in the equilibrium layer can be used as the starting point in the analysis as shown by the results of Figs 8-11. This is true despite some rather strong effects of secondary circulation on the Reynolds stresses $\overline{u w}$ (Fig. 8), with the data from profiles in the upflow regions $(y / b=0.28$ to 0.23 in the low flow case and $y / b=0.5$ to 0.45 in the high flow case) plotting above Eq. (3) and data in the downflow areas $(y / b=0.5$ to 0.45 in the low flow case and $y / b=0.34$ to 0.23 in the high flow case) plotting below Eq. (3), in total agreement with Nezu and Nakagawa (1993). The differences with Eq. (3) are quite substantial, as much as $\pm 50 \%$ for the low flow case and $\pm 80 \%$ for the high flow case. Figures 9 and 10 present considerable scatter in the experimental points due to the computation of gradients in the vertical direction (data points are $1 \mathrm{~cm}$ apart) but they show trends consistent with the analytical expression of Eq. (4). More importantly, streamwise turbulent intensities closely follow the predictions of both Eqs (5) and (7). In addition, the simplified model for turbulence anisotropy used by Ikeda (Eq. (10)) seems to provide a reasonable approximation to the measured data (Fig. 12). The fitting is not as good close to the bed, but this was expected since Eq. (10) is not valid for $z / h<0.3$. Higher values of anisotropy in this zone are due to the damping of $w^{\prime 2}$ (Nezu and Nakagawa, 1993).

In short, all the data show a behavior compatible with the turbulence-induced secondary circulation. However, the current accepted theory for this type of flow situation-based largely on smooth bed conditions - would only predict such secondary currents for $b / h$ ratios of 5 or less. For higher ratios, as the ones corresponding to the present experiments $(b / h=8.5$ and 6.3 for low- and high-flow conditions, respectively), either a weak or inexistent secondary circulation pattern would be expected in the central region of the channel. According to Nezu and Nakagawa (1993), a stable secondary circulation pattern requires some reinforcing mechanism beyond $y / h=2.5$ from the side walls, which can be provided by oscillations on the bed shear stress or longitudinal ridges and troughs (Nezu and Nakagawa, 1984, 1993; Studerus, 1982). This later mechanism was highly unlikely to take place in the present experiments as no re-working of the bed occurred and no sorting or topographic variations were observed.

Having said that, the results presented here and previous observations of flows with similar bed roughness and relatively smooth walls (Naot, 1984; Tominaga et al., 1989) show a reinforcement of the secondary flow patterns. Since turbulence anisotropy at the bed does not seem to be enhanced by the presence of roughness (in fact Nezu and Nakagawa (1993) speculates on the possibility of a reduced anisotropy due to roughness) the most likely mechanism for the maintenance of the cellular pattern throughout the cross section is the strengthening of the corner surface vortex. This fact has been observed before (Naot, 1984; Tominaga et al., 1989) but has not been proposed as an effective mechanism. The present experiments show no evidence of the existence of a bottom vortex at the corner (or close to it, as the measurements could not get closer than $7 \mathrm{~cm}$ from the walls), which leads to the assumption that the surface vortex - enhanced by a strong upward flow over the smooth wall-is substantially stronger than in the smooth bed situation. This additional strength reinforces the secondary circulation pattern, and seems to be enough to compensate for the expected decay with distance from the wall. This is valid for the present conditions only, and more research is needed (on a wider channel) to clarify how far from the walls this mechanism is still effective. If the surface vortex plays such a role there is in fact transverse transport of vorticity from the walls toward the channel centerline, which is not accounted for by an equation like Eq. (8). A more complete vorticity equation including transverse pressure gradients or body forces acting on the mean shear can account for such redistribution of vorticity (Perkins, 1970), and that would raise the question of whether or not the present secondary circulation is truly turbulence-induced or has an additional component.

Of course there may be other factors interacting with the bed and wall in order to produce the observed flow pattern. Studies on turbulent coherent macro structures have shown that even if the long time averaged flow does not show a clear secondary circulation, unstable and instantaneous secondary currents in the form of longitudinal vortices are always present (Imamoto and Ishigaki, 1986; Tamburrino and Gulliver, 1999; Schvidchenko and Pender, 2001; Onitsuka and Nezu, 2001; Roy et al., 2004). Due to their unsteady character (lateral shifting), these macro turbulent structures sometimes cannot be detected by a temporal mean analysis (Nezu, 2005). The main apparent feature of these structures, often observed in the field (Kinoshita, 1984), is the presence of boils (called boils of the second kind) in the low-speed areas associated with upwelling (Jackson, 1976). Roughness may also have an effect on the macro turbulent structures: experimental evidence suggests that depth-scale longitudinal eddies are more stable (with less lateral shifting) over a rough bed than over a smooth bed (Imamoto and Ishigaki, 1986; Schvidenko and Pender, 2001) and therefore their associated secondary currents 


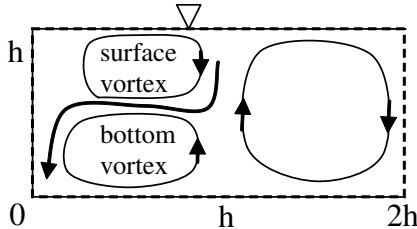

Smooth bed open channel

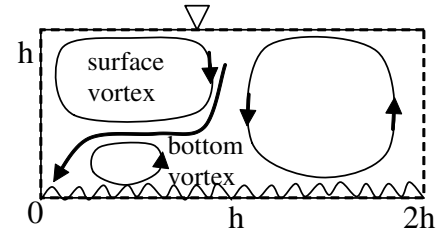

Rough bed open channel

Figure 14 Secondary circulation close to walls in smooth and rough bed open channels

may be detected by temporal mean analysis. Explanation and consequences of this phenomenon are still lacking, in particular since the smooth wall effect (with a strong surface vortex) in the laboratory experiments that led to that conclusion cannot be ruled out.

The results also imply that if high flow conditions are used for the design of any in-channel structure, an area of high bottom shear stress is going to develop at a distance of about $h$ from the river banks. In this regard, the rough bed situation in which the surface vortex dominates is potentially more dangerous for the stability of the banks than a smooth bed case in which the bottom vortex prevails, due to the position of the induced secondary circulation and associated downwelling regions with high shear stress. Figure 14 shows that for smooth bed downwelling occurs at a larger distance from the bank (about $2 h$ ) than for rough bed. Roughening of the bank to achieve the same roughness than the bed can be a way of preventing the strengthening of the surface vortex and thus improve bank stability, as shown by some of the results of Naot (1984) and Tominaga et al. (1989).

Regarding the usefulness of the present experiments as the background condition before introducing additional flow variability, the results are very valuable since they show a secondary circulation pattern which is stronger than would be expected according to some of the existing literature. This 3D flow pattern is the result of the particular conditions of the experiments in terms of roughness differences between walls and bed and is expected to persist in future experiments in the same facility as long as the roughness conditions remain unchanged. The secondary flow pattern observed, while substantial, does not provide the level of spatial variability required for the enhancement of in-stream habitat. Pool and riffle sequences-with their streamwise variations in the cross section-generate a wider variety of flow velocities that are necessary to grant acceptable habitat conditions.

\section{Conclusions}

Experiments on a rectangular channel over a rough, flat bed with smooth lateral walls have shown consistency with the very few results reported in the literature. The patterns of streamwise velocity and secondary circulation are well defined and differ from one experiment to another, presenting a cellular structure that scales with flow depth. Streamwise velocities show cores up to $10 \%$ faster than the surrounding flow and secondary currents are of the order of $5 \%$ of the mean streamwise velocity.

The secondary flow redistributes momentum, and this could be seen in the streamwise Reynolds stress distribution. The downflows transports high momentum fluid toward the bottom resulting in an incursion of the higher velocities into regions close to the bed and an associated increase in the bed shear stresses. The upflows transport momentum away from the bottom into the water column and reduces the bed shear stresses. These variations in the bed shear stress are of the order of $20 \%$ of the cross-sectional averaged value.

The data show a behavior compatible with the turbulenceinduced secondary circulation. However, the existence of different roughnesses in bed and walls has an impact in the secondary flow patterns and is reflected in the bed shear stress distribution, with a very marked oscillation that does not appear to get weaker away from the lateral walls. A strong surface vortex at the wall is proposed as the main mechanism responsible for this behavior. Ikeda's simple model of secondary circulation can still be applied to regions away from the wall in the present situation as long as the measured wall shear stress distribution is specified.

The present results are applicable to channelized urban streams in which the bed is considerable rougher than the lateral walls, and constitute the baseline for further investigations on artificially induced secondary currents and flow variability in stream restoration projects.

\section{Acknowledgements}

Félix López provided invaluable help during the execution of the experiments. Partial financial support was provided by the project "Development of an Integrated Scientific and Technological Framework for Stream Naturalization," Grant 98-NCERQA-M1, US. Environmental protection Agency (EPA). The work was completed while the first author was on sabbatical leave from the University of Newcastle, Australia, at the University of Illinois at Urbana-Champaign.

\section{References}

Choi, S., Moonhyeong, P., Hyeonsik, K. (2006). Numerical simulations of flow and suspended sediment transport in open channel flows over smooth-rough bed strips. ICHE 2006, Seventh International Conference on Hydro-Science and Engineering, Philadelphia, USA.

Chow, V.T. (1959). Open Channel Hydraulics, McGraw-Hill, New York.

Einstein, H.A., Li, H. (1958). Secondary currents in straight channels. Trans. Amer. Geophys. Union 39, 1085-1088.

Garcia, M.H. (1999). Sedimentation and erosion hydraulics, In: Larry Mays (ed.), Hydraulic Design Handbook, Chapter 6, McGraw-Hill, Inc., 6.1-6.113.

Garcia, C.M., Cantero, M, Niño, Y., Garcia, M.H. (2005). Turbulence measurements using acoustic doppler velocimeters. J. Hydraul. Engng., ASCE 131, 1062-1073. 
Gibson, A.H. (1909). On the depression of the filament of maximum velocity in a stream flowing through an open channel. Proc. Royal Soc. of London, Series A 82, 149-159.

Ikeda, S. (1981). Self forced straight channels in sandy beds. J. Hydraul. Div. ASCE 107 (HY4), 389-406.

Imamoto, H., Ishigaki, T. (1986). Visualization of longitudinal eddies in an open-channel flow. In: Veret C. (ed), Flow Visualization IV, Proc. 4th Int. Symp. on Flow Visualization, Hemisphere, Washington D.C., 323-337.

Jackson, R.G. (1976). Sedimentological and fluid dynamics implications of the turbulent bursting phenomenon in geophysical flows. Journal of Fluid Mechanics 77, 531-560.

Jin, Y., Zarrati, A., Zheng, Y. (2004). Boundary shear distribution in straight ducts and open channels. J. Hydraul. Engng., ASCE 130(9), 924-928.

Kinoshita, R. (1984). Present status and future prospects of river flow analysis by the aerial photograph. Proc. Japan Soc. Civil Engrs. 345, 1-19.

Lopez, F., Garcia, M.H. (1999). Wall similarity in turbulent openchannel flow. J. Eng. Mech., ASCE 125(7), 789-796.

McLean, S.R. (1981). The role of non-uniform roughness in the formation of sand ribbons. Marine Geol. 42, 49-74.

McLelland, S.J., Ashworth, P.J., Best, J.L., Livesey, J.R. (1999). Turbulence and secondary flow over sediment stripes in weakly bimodal bed material. J. Hydraul. Engng., ASCE 125(5), 463-473.

Naot, D. (1984). Response of channel flow to roughness heterogeneity. J. Hydrual. Div., ASCE 110(11), 1568-1587.

Naot, D., Rodi, W. (1982). Calculation of secondary currents in channel flow. J. Hydraul. Div., ASCE 108(8), 948-968.

Nezu, I. (2005). Open-channel flow turbulence and its research prospect in the 21st century. J. Hydraul. Engng., ASCE 131(4), 229-246.

Nezu, I., Nakagawa, H. (1984). Cellular secondary currents in a straigth conduit. J. Hydraul. Engng., ASCE 110(2), 173-193.

Nezu, I., Nakagawa, H. (1993). Turbulence in Open Channel Flows. A. A. Balkema, Rotterdam, The Netherlands.

Nezu, I., Rodi, W. (1985). Experimental study on secondary currents in open channel flow. Proc. 21st IARH Congress, Melbourne, 2, 19-23.

Nikuradse J. (1933). Strömungsgesetze in rauhen Rohren. Forsch. Geb. Ingenieurwes., Ausg. Beill. 4, 361 (English translation: NACA Technical Memorandum, 1291).

Onitsuka, K., Nezu, I. (2001). Generation mechanism of turbulence driven secondary currents in open-channel flows. In: Kambe, K. et al. (eds), IUTAM Symp. Geometry and Statistics of Turbulence, Kluwer Academic, Boston, 345-350.
Prandtl, L. (1952). Essentials of fluid dynamics, Blackie and Son, London, 452.

Perkins, H.J. (1970). The formation of streamwise vorticity in turbulent flow. J. Fluid Mech. 44, 721-740.

Rodríguez, J.F., García, M.H., Bombardelli, F.A., Guzmán, J.M., Rhoads, B.L., Herricks, E. (2000). Naturalization of urban streams using in-channel structures. Proc. Joint Conference on Water Resources Engineering and Water Resources Planning and Management, ASCE, Minneapolis, MN.

Rodríguez, J.F., López, F.M., García, C.M., García, M.H. (2003). Laboratory experiments on pool-riffle sequences designed to restore channelized low-gradient streams. In: Clar, M., Carpenter, D. Gracie, J., Slate, L. (eds), In Protection and Restoration of Urban and Rural Streams, ASCE.

Rodríguez, J.F., García, C.M., López, F.M., García, M.H. (2004). Effects of bed topography and vegetation on 3D flow patterns in low-gradient rivers. ICHE 2004, Sixth International Conference on Hydro-Science and Engineering, Brisbane, Australia.

Roy, A.G., Buffin-Bélanger, T., Lamarre, H., Kirkbride, A.D. (2004). Size, shape and dynamics of large scale turbulent flow structures in a gravel bed river. J. Fluid Mech. 500, 1-27.

Schlichting, H. (1979). Boundary Layer Theory, McGraw-Hill, New York.

Schvidchenko, A. B., Pender, G. (2001). Macroturbulent structure of open-channel flow over gravel beds. Water Resour. Res. 37(3), 709-719.

Smart, G.M. (1999). Turbulent velocity profiles and boundary shear in gravel bed rivers. J. Hydaul. Engng. 125(2), 106-116.

Studerus, X. (1982). Sekundärströmungen im offenen Gerinne über rauhen Längsstreifen. $\mathrm{PhD}$ thesis, ETH, Zürich, Switzerland.

Tamburrino, A., Gulliver, J. S. (1999). Large flow structures in a turbulent open channel flow. J. Hydraul. Res. 37(3), 363-380.

Tominaga, A., Nezu, I., Ezaki, K., Nakagawa, H. (1989). Three dimensional turbulent structure in straight open channel flows. J. Hydraul. Res. 27(1), 149-173.

Townsend A.A. (1976). The Structure of Turbulent Shear Flow, (2nd edn). Cambridge University Press.

Vanoni, V.A. (1975). Sedimentation Engineering. Manual 54, ASCE.

Wade, R.J., Rhoads, B.L., Rodríguez, J.F., Newell, M., Wilson, D., Herricks, E., Bombardelli, F.A., García, M.H. (2002). Integrating science and technology to support stream naturalization near chicago, illinois. Journal of the AWRA 38(4), 931-945. 